\title{
CD8+CD39+ T Cells Mediate Anti-Tumor Cytotoxicity in Bladder Cancer
}

This article was published in the following Dove Press journal: OncoTargets and Therapy

\author{
Wenjie Zhu' ${ }^{\mathrm{l} *}$ \\ Zihan Zhao (D) ${ }^{1, *}$ \\ Baofu Feng ${ }^{2}$ \\ Wenhao $\mathrm{Yu}^{3}$ \\ $\mathrm{Ji} \mathrm{Li}^{3}$ \\ Hongqian Guo' \\ Rong Yang'
}

'Department of Urology, Nanjing Drum Tower Hospital, The Affiliated Hospital of Nanjing University Medical School, Institute of Urology, Nanjing University, Nanjing, 210008, People's Republic of China; ${ }^{2}$ Department of Urology, Nanjing Drum Tower Hospital Clinical College of Nanjing Medical University, Nanjing, 2 I0008, People's Republic of China; ${ }^{3}$ State Key Laboratory of Coordination Chemistry, Chemistry and Biomedicine Innovation Center (ChemBIC), School of Chemistry and Chemical Engineering, Nanjing University, Nanjing, 210023,

People's Republic of China

*These authors contributed equally to this work

Correspondence: Rong Yang; Hongqian Guo

Email doctoryr@gmail.com; dr.ghq@nju. edu.cn
Introduction: Although immunotherapy works well in parts of patients with bladder cancer (BLCA), its overall response rate of anti-PD-1 inhibitors remains unsatisfactory. Besides, growing evidence shows that tumor-infiltrating lymphocytes (TILs) immunotherapy has demonstrated excellent efficacy in various cancers. Considering the huge heterogeneity and low overall survival rate of BLCA, it is urgent to explore the new immune checkpoints (ICs) or TILs therapy to improve the survival prognosis for BLCA patients.

Materials and Methods: The public bioinformatics databases were used to explore the prognostic value of 5 potential ICs targets (TIM-3, LAG-3, OX40, 4-1BB and CD39). A total of 46 BLCA patients undergoing surgical treatment at our hospital from May 2020 to October 2020 were enrolled in this study. The expressions of PD-1, TIM-3, LAG-3, OX40, 4-1BB, and CD39 in T cells of BLCA patients were explored by flow cytometry, and the correlation between different subgroups of T cells and clinicopathological parameters was analyzed. Besides, the mouse CD4+CD39+ T cells, CD4+CD39- T cells, CD8+CD39+ $\mathrm{T}$ cells, and CD8+CD39- T cells were sorted and co-cultured with MB49 bladder cancer cell lines in vitro to investigate the potential biomarker of tumor-reactive TILs.

Results: Public bioinformatics databases analyses show that only the high expression of CD39 was significantly associated with advanced tumor stage $(P<0.001)$ and tend to result in a worse survival rate. In our study, the elevated expression of CD39 in CD4+/CD8+ $\mathrm{T}$ cells were significantly associated with the pathological $\mathrm{T}$ stage $(\mathrm{pT}<2, P=0.041)$ and papillary tumor $(P=0.038)$. Moreover, the $\mathrm{CD} 8+\mathrm{CD} 39+\mathrm{T}$ cells showed a stronger tumorkilling effect and produced a higher level of IFN- $\gamma$ than other T cell populations.

Conclusion: CD39 may be a potential prognostic marker in BLCA, and CD8+CD39+ $\mathrm{T}$ cells may be selected as tumor-reactive and killing $\mathrm{T}$ cells for TILs therapy.

Keywords: CD8, CD39, T cells, anti-tumor cytotoxicity, bladder cancer, immunotherapy, TILs, immune checkpoint

\section{Introduction}

Bladder cancer (BLCA) is the most common malignant tumor of the urinary system, and it is also the 12 th most common cause of cancer death in the world. ${ }^{1}$ Although more than $60 \%$ of tumors were diagnosed as the non-muscle invasive stage at the first time of diagnosis, approximately $15 \%-40 \%$ of patients developed muscle-invasive stage or metastatic stage after surgical operation. $^{2}$ For advanced bladder cancer, cisplatin-based combination chemotherapy is the first-line treatment option. Although the overall response rate of chemotherapy is acceptable, the toxic side effects are so severe that most patients can only receive less than six cycles of treatment, with a median 
survival of only 15 months. ${ }^{3}$ So more alternative treatment options are still underscored.

In recent years, immunotherapy by changing the immune status of patients has occupied an increasingly important position in tumor treatment, including immune checkpoint inhibitors (ICIs) therapy, adoptive cell therapy (ACT), monoclonal antibodies, and vaccines. Among these treatments, the programmed cell death protein 1 (PD-1) checkpoint inhibitors have been approved for the treatment of BLCA, but it is only effective in specific patients. Prior studies indicate that PD-1+ T cells demonstrated varied responses to anti-PD-1 treatment, ${ }^{4}$ and the response rate of PD-1 blockade is less than $30 \%,{ }^{5}$ which may be due to the heterogeneity of tumor immune microenvironment (TME) and phenotypic characteristics of tumor-infiltrating lymphocytes (TILs). Therefore, new immune checkpoints (ICs) are still awaiting to be discovered to improve the survival prognosis of BLCA patients.

Since the discovery and characterization of PD-1, kinds of ICs have been investigated including T-cell membrane protein 3 (TIM-3, encoded by HAVCR2), ${ }^{6}$ lymphocyte activation gene 3 (LAG-3), ${ }^{6}$ costimulatory molecule CD134 (OX40, encoded by TNFRSF4), ${ }^{7}$ cluster of differentiation 137 (CD137 (4-1BB), encoded by TNFRSF9), ${ }^{8}$ ectoenzyme CD39 (encoded by ENTPD1), ${ }^{9}$ and so on. Although these biomarkers have been studied deeply in other cancers and corresponding clinical trials have been carried out, there are few studies in BLCA.

Recently, another tumor immunotherapy method, ACT (including CAR-T (Chimeric Antibody Receptor Engineered T Cell), TCR-T (Engineered T Cell Receptor T Cell), TILs (tumor invasive lymphocytes)), has solved the difficult problem of $\mathrm{T}$ cell recognizing tumors at different levels, and gradually demonstrated excellent efficacy in clinical trials. ${ }^{10-12}$ Compared with CAR-T and PD-1/PDL1 antibodies, TILs had the advantages of multi-target, stronger tumor tendency and infiltration ability, and fewer side effects. However, TILs are a heterogeneous population, and thus enrichment of the final product in neoantigenreactive $T$ cells may enhance clinical efficacy. In this regard, PD-1 and 4-1BB have been proposed as markers for the tumor-reactive repertoire in the tumor. ${ }^{13,14}$ Nonetheless, considering the huge heterogeneity of patients, only PD-1 and $4-1 \mathrm{BB}$ as tumor-reactive biomarkers of TILs are not enough.

Therefore, we explored the role of these ICs in BLCA in this study. We first analyzed the transcriptional expression of these biomarkers in BLCA and the relationship between these ICs and BLCA patients' prognosis by using public bioinformatics databases. Interestingly, we found that only the mRNA expression of CD39 is associated with the tumor stage and higher expression of CD39 with lower survival rate, which was opposite to the recent research. ${ }^{15,16}$ Thus, we further explored the PD-1, TIM-3, LAG-3, OX40, 4-1BB, and CD39 expressions in T cells, especially in $\mathrm{CD} 4+/ \mathrm{CD} 8+\mathrm{T}$ cells by flow cytometry. Moreover, we identified that the $\mathrm{CD} 8+\mathrm{CD} 39+\mathrm{T}$ cells were the tumor-reactive and killing population in BLCA, which may be a potential prognostic marker in BLCA, and it also can be an effective marker to select the real active $\mathrm{T}$ cells for TILs therapy.

\section{Materials and Methods Public Databases UALCAN Analysis}

UALCAN (http://ualcan.path.uab.edu/index.html) is a convenient web-portal that provides analysis of transcriptional expressions based on The Cancer Genome Atlas (TCGA) database. ${ }^{17}$ In our study, UALCAN was used to evaluate the mRNA expressions of these immune checkpoints (TIM-3, LAG-3, OX40, 4-1BB, and CD39) between normal tissues and tumor samples. The difference was compared by Student's $t$-test and the $P$ value was set as 0.05 .

\section{The Kaplan-Meier Plotter Analysis}

The prognostic value of mRNA expression of these immune checkpoints in BLCA was analyzed by KaplanMeier plotter (https://kmplot.com/analysis/), an online prognostic analysis tool, which contains transcription expression data and survival condition of 408 BLCA patients. ${ }^{11}$ The BLCA patients were divided into high and low expression groups according to the "auto select best cutoff" and assessed by a Kaplan-Meier survival curve to evaluate the overall survival (OS), with a hazard ratio (HR) with $95 \%$ confidence intervals (CIs) and $\log$ rank $P$ value. The $P$ value $<0.05$ was considered as statistical significance.

\section{GEPIA Analysis}

Gene Expression Profiling Interactive Analysis (GEPIA, http://gepia.cancer-pku.cn/index.html) is an online mRNA data analysis tool based on 9736 tumors and 8587 normal samples. ${ }^{18}$ At present study, we performed an mRNA expression level analysis of the pathological stage by the "Single Gene Analysis" module of GEPIA. 


\section{Patients and TILs Isolation}

Patients

This study included 46 BLCA patients undergoing surgical treatment at the Department of Urology, Nanjing Drum Tower Hospital (Nanjing, China) from May 2020 to October 2020. Patients with unclear tumor grade, the presence of other cancers was excluded $(n=4)$. A total of 42 patients' clinicopathological information were recorded, including age diagnosis of BLCA, gender, pathologic tumor $\mathrm{T}$ stage ( $\mathrm{pT}<2$ or $\mathrm{pT} \geq 2$ ), tumor grade (evaluated by the WHO International Society of Urological Pathology consensus classification), tumor histology (papillary tumor or non-papillary tumor).

\section{T Cells Isolation}

To obtain the T cells, the tumor tissues were collected during surgical operation and preserved in the T cell medium, and tumor tissues were prepared as follows: under sterile conditions, tumors were cut into small pieces and digested in RPMI-1640 medium supplemented with collagenase IV at $1 \mathrm{mg} / \mathrm{mL}$ (Sigma), DNase at $30 \mathrm{U} / \mathrm{mL}$ (Sigma) at $37^{\circ} \mathrm{C}$ for 30 to 45 minutes. Digested tissues suspensions were filtered through a $70 \mu \mathrm{m}$ filter and washed in RPMI-1640 medium $+5 \%$ FBS + DNase $(15 \mathrm{U} / \mathrm{mL})$. After the above operations, TILs were obtained and stained by flow cytometry. All TILs were cryopreserved until further analysis.

\section{Flow Cytometry}

The following fluorescent-labeled antibodies were used: AlexaFluor (AF)-700 anti-human CD3 (HIT3; 1:100\#300324), Pacific Blue anti-human CD4 (OKT4; 1:100\#317429), PE anti-human CD8 (HIT8a; 1:100-\#300908), AlexaFluor (AF)-647 anti-human PD-1 (EH12.2H7; 1:100\#329904), PE/Cyanine5 anti-human CD366 (Tim-3) (F382E2; 1:100-\#345052), PE/Cyanine7 anti-human CD223 (LAG-3) (11C3C65; 1:100-\#369310), Brilliant Violet 711 anti-human CD134 (OX40) (Ber-ACT35; 1:100-\#350030), APC/Cyanine7 anti-human CD137 (4-1BB) (4B4-1; 1:100\#309830), and Brilliant Violet 605 anti-human CD39 (A1; 1:100-\#328236). APC anti-mouse CD4 (GK1.5; 1:100\#100412), Pacific Blue anti-mouse CD8a (53-6.7; 1:100\#100725), and PE/Cyanine7 anti-mouse CD39 (Duha59; 1:100-\#143806) were used to sorted the CD4+CD39+ $\mathrm{T}$ cells, CD4+CD39- $\mathrm{T}$ cells, CD8+CD39+ $\mathrm{T}$ cells, and CD8+CD39- $T$ cells. Zombie Aqua Fixable Viability Kit was used to distinguish viable cells (Biolegend). Cell surface staining was performed in FACS buffer (PBS, supplemented with $2 \%$ FBS). Wash cells with PBS buffer and resuspend
$1-10 \times 10^{\wedge} 6$ cells in diluted $100 \mu \mathrm{L}$ antibodies solution. Incubate the cells at $4^{\circ} \mathrm{C}$, in the dark, for 30 minutes. Wash twice with FACS buffer, then the cells can be analyzed, and the gated strategy of different population $T$ cells was shown in Supplement Figure 1.

\section{Anti-Tumor Cytotoxicity Assays}

The animal experiments were approved by the Institutional Review Board of Nanjing University (Nanjing, China), the 6-8 weeks-old female C57BL6/J mice was purchased from the Model Animal Research Center of Nanjing University (Nanjing, China), and all the animals were used in accordance with the recommendations outlined in the Guide for the Care and Use of Laboratory Animals of the National Institutes of Health. $2 \times 10^{\wedge} 6$ MB49 cells were resuspended in $100 \mu \mathrm{L}$ of DPBS and inoculated subcutaneously on the right inguinal side of C57/B6 mice. When the diameter of the tumor was about $8 \mathrm{~mm}$, the mice were euthanized to remove the tumor. The tumor was ground in $5 \mathrm{~mL} \mathrm{~T}$ cell culture medium and filtered through a $70 \mu \mathrm{m}$ filter. Purify TILs with percoll (SigmaAldrich), and Dilute to $1 \sim 2 \times 10^{\wedge} 6$ live cell $/ \mathrm{mL}$. Add human IL-2 to a final concentration of $100 \mathrm{IU} / \mathrm{mL}$ and rest in the incubator overnight. Obtained CD4+CD39+ $\mathrm{T}$ cells, CD8+CD39+ $\mathrm{T}$ cells, CD4+CD39- $\mathrm{T}$ cells, CD8 +CD39- $\mathrm{T}$ cells by fluorescence-activated cell sorting. To assess $\mathrm{T}$ cell killing of autologous tumor cells, 5000-10000 tumor cells were seeded in triplicate into an RTCA E-plate (Agilent) to reach $10 \%$ confluence. Expanded autologous $\mathrm{T}$ cells subsets were counted and 1 $\times 10^{\wedge} 5 \mathrm{~T}$ cells were cultured with tumor cells in medium without any interleukin (T cells: tumor cell ratio of 10:1). Use xCELLigence RTCA TP for cell killing detection.

According to the result of the tumor cell killing experiment, we re-sorted the CD8+CD39+ T cells and CD8+CD39T cells to confirm the function of CD39 expression in CD8+ $\mathrm{T}$ cells. The process as mentioned before, and the supernatants were harvested and analyzed by enzyme-linked immunosorbent assay (ELISA, Mouse IFN- $\gamma$ ELISA Kit, 4abio, \#CME0003) to analyze the secretion of IFN- $\gamma$.

\section{Statistical Analysis}

GraphPad Prism 8.0 was used to perform all statistical analyses. The correlation between different subgroups $\mathrm{T}$ cells and clinicopathological parameters was evaluated by Spearman's test and Mann-Whitney $U$-test, and the relationship between these immune checkpoints was assessed by 
Pearson's test. All statistical analyses were two-sided and $P$ value $<0.05$ was considered as a statistical difference.

\section{Results}

\section{Bioinformatics Analysis of Immune Checkpoints}

At present study, we first investigated the difference between mRNA expression of TIM-3, LAG-3, OX40, 4-1BB and CD39 in normal bladder tissues and BLCA tissues by UALCAN analysis. The transcriptional expression levels of LAG-3 $(P<0.01$, Figure 1B) and CD39 $(P<0.01$,
Figure 1E) in BLCA tissues were found to be significantly downregulated while the mRNA expression levels of TIM-3 $(P<0.01$, Figure 1A), 4-1BB $(P<0.05$, Figure 1D) were significantly elevated, and the transcriptional expression of OX40 shows no significant difference between normal bladder tissues and BLCA tissues (Figure 1C). We next analyzed the correlation between mRNA expression of these ICs and tumor stage by GEPIA dataset. As shown in Figure 2, mRNA expression of TIM-3 $(P<0.05), 4-1 \mathrm{BB}(P<$ $0.05)$, and $\operatorname{CD} 39(P<0.001)$ were remarkably associated with patients' tumor stage, especially in patients who were in advanced tumor stage tended to express increased
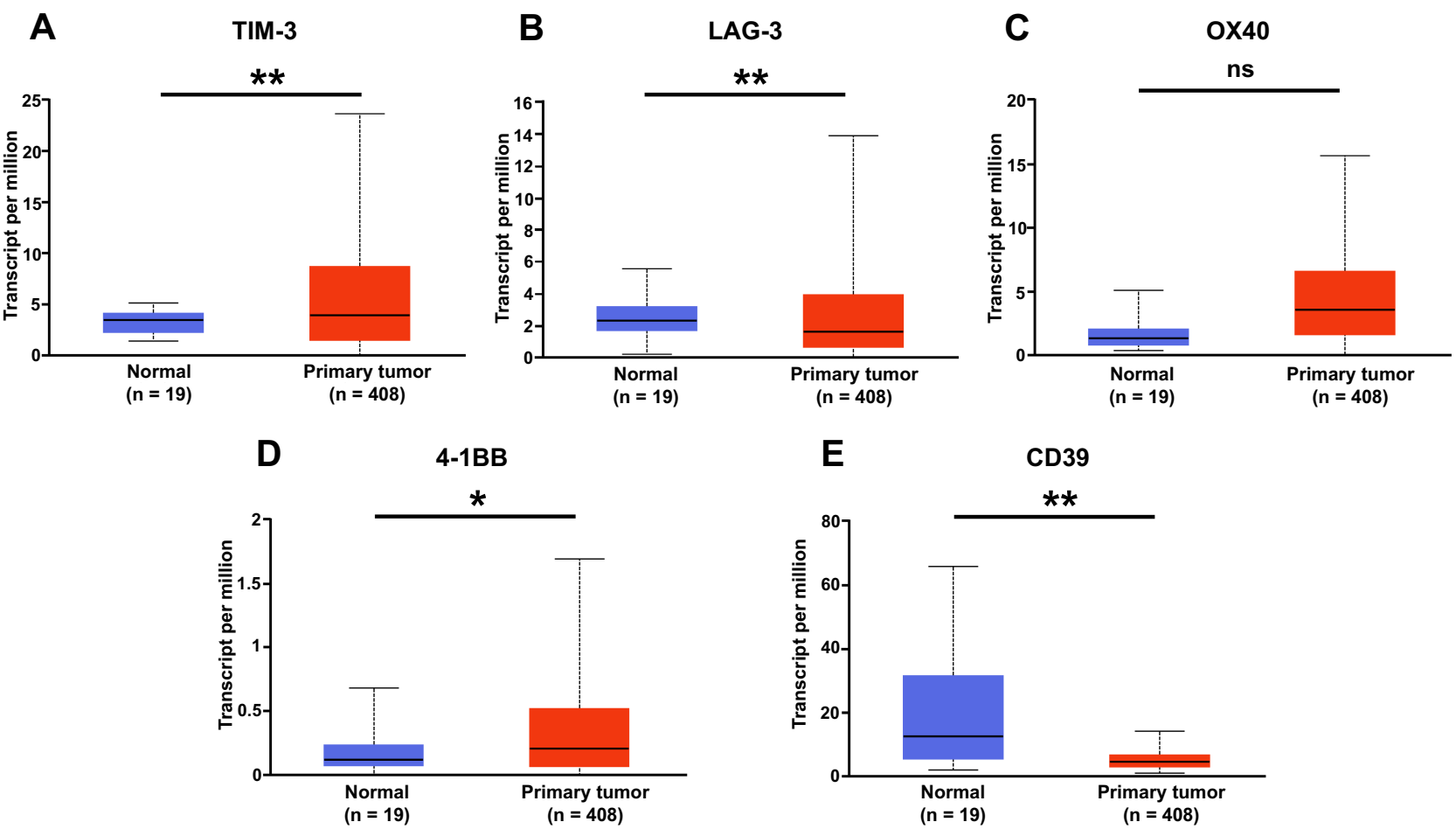

Figure I The transcriptional levels of 5 potential immune checkpoints in BLCA (UALCAN). (A) TIM-3, (B) LAG-3, (C) OX40, (D) 4-IBB, (E) CD39. The transcriptional levels of (B) LAG-3 and (E) CD39 in BLCA tissues were significantly reduced while the transcriptional levels of (A) TIM-3 and (D) 4-IBB were significantly elevated, and the transcriptional expression of $(\mathbf{C})$ OX40 shows no significant difference in normal bladder tissues and BLCA tissues. $* P<0.05 ; * * P<0.0$; ; ns, $P>0.05$.
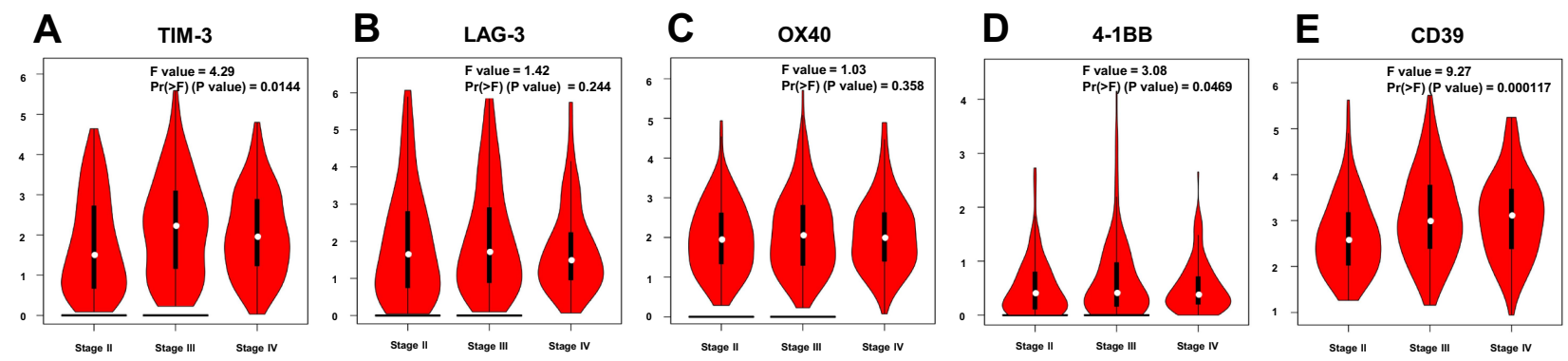

Figure 2 Relationship between mRNA expression of 5 potential immune checkpoints and the pathological stage of BLCA patients (GEPIA). (A) TIM-3, (B) LAG-3, (C) OX40, (D) 4-IBB, (E) CD39. The mRNA expression of (A) TIM-3, (D) 4-IBB, and (E) CD39 were remarkably associated with patients' tumor stage, and the distribution of (B) LAG-3 and (C) OX40 were not related to tumor grades. 
transcriptional expression of CD39 (F value $=9.27, P<$ 0.001 , Figure 2E). Moreover, we further explored the prognostic value of mRNA expression of these ICs in BLCA patients using the Kaplan-Meier Plotter database (Figure 3). The Kaplan-Meier curve analysis revealed that BLCA patients with higher mRNA expression of CD39 may obtain worse survival rate (Figure 3E), while the patients with higher mRNA expression of other immune checkpoints tended to get longer overall survival. To explore the reason for the difference between CD39 and other ICs, we further explored these ICs expressions in BLCA patients.

\section{Patients and Tumor Characteristics}

Table 1 lists the clinical and pathological features of 42 patients. The median age of this cohort was 67 years (range: 39-86), and most of the patients were male $(83 \%)$. There were $31(74 \%)$ patients with high-grade tumors and $11(26 \%)$ patients with low-grade tumors. Pathologic T stage (pT stage) $>$ T2 was diagnosed in 13 (31\%) patients and $29(69 \%)$ cases were diagnosed as < T2. In all, $28(67 \%)$ patients had papillary tumor, and 14 $(33 \%)$ patients with Non-papillary tumor.

\section{Distribution of Immune Checkpoints Expression of CD4+/CD8+ T Cells}

The distribution of these ICs expressions of CD4+/CD8+ $\mathrm{T}$ Cells in BLCA patients of different tumor grades, tumor stages, and tumor histology were described by t-distributed stochastic neighbor embedding (t-SNE) map (Figure 4), which revealed that individual tumors were made up of highly heterogeneous cell populations in BLCA. We firstly analyzed the relationship between different types of $\mathrm{T}$ cells and tumor grade (Figure 5A), tumor pathologic $\mathrm{T}$ stage
A

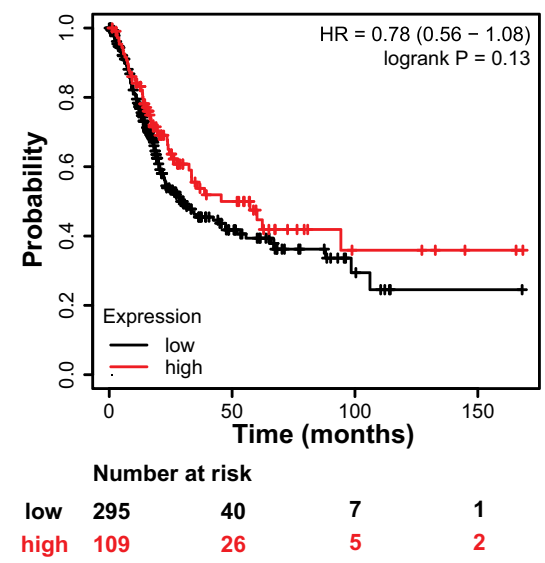

B

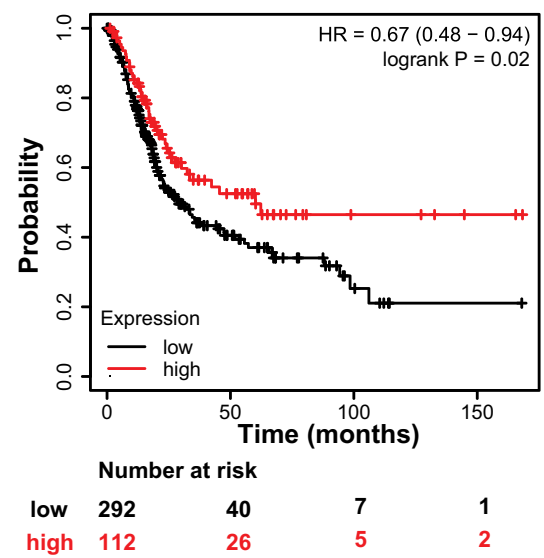

C

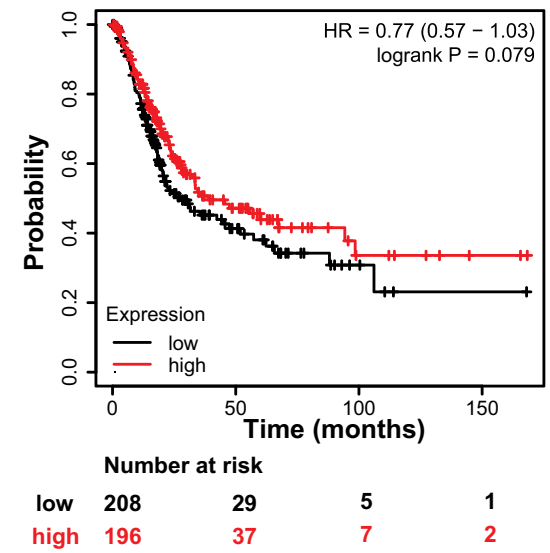

D 4-1BB

E CD39
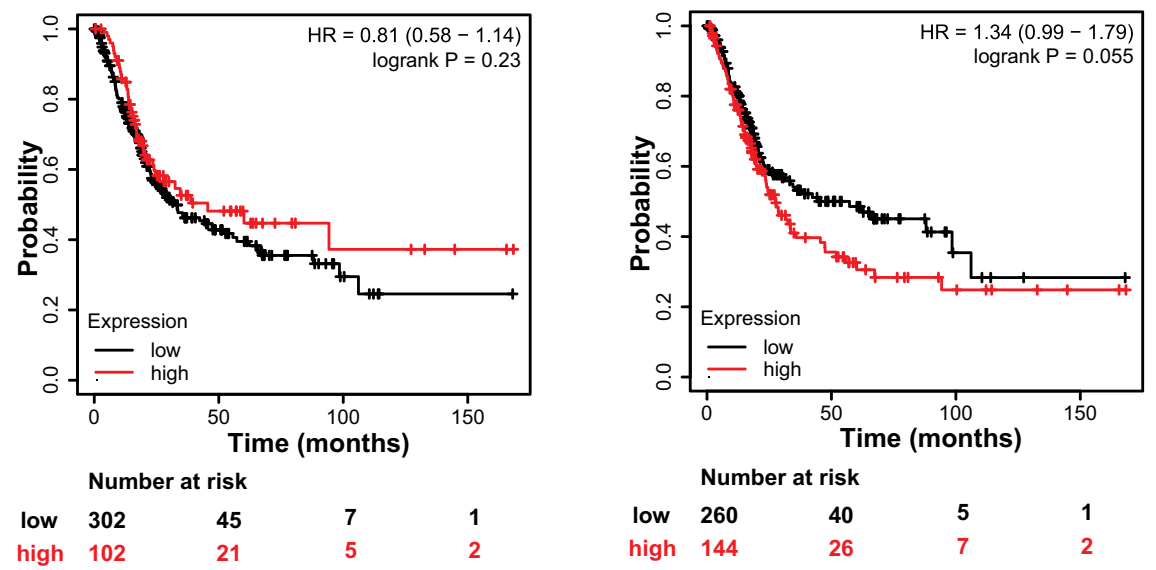

Figure 3 Prognostic value of mRNA expression of 5 potential immune checkpoints in BLCA patients in the overall survival analysis (Kaplan-Meier Plotter). (A)TIM-3, (B) LAG-3, (C) OX40, (D) 4-IBB, (E) CD39. Generally, higher mRNA expressions of (A)TIM-3, (B) LAG-3, (C) OX40, and (D) 4-IBB may result in better overall survival of BLCA patients. However, the BLCA patients with higher mRNA expression of (E) CD39 may have worse survival rate. 
Table I Clinicopathologic Parameters for the Overall Cohort of 42 Patients with BLCA

\begin{tabular}{|c|c|c|}
\hline Parameters & & All Patients (\%) \\
\hline \multirow[t]{2}{*}{ Age } & Young (< 67 years) & $21(50 \%)$ \\
\hline & Old ( $\geq 67$ years) & $21(50 \%)$ \\
\hline \multirow[t]{2}{*}{ Gender } & Male & 35 (83\%) \\
\hline & Female & 7 (17\%) \\
\hline \multirow{2}{*}{ Grade } & High & 31 (74\%) \\
\hline & Low & II (26\%) \\
\hline \multirow[t]{2}{*}{ pT stage } & $<\mathrm{T} 2$ & 29 (69\%) \\
\hline & $\geq \mathrm{T} 2$ & $13(31 \%)$ \\
\hline \multirow[t]{2}{*}{ Tumor histology } & Papillary & $28(67 \%)$ \\
\hline & Non papillary & 14 (33\%) \\
\hline
\end{tabular}

Abbreviations: BLCA, bladder cancer; ICls, immune checkpoint inhibitors; TILs, tumor-infiltrating lymphocytes; PD-I, programmed cell death protein I; TME, tumor immune microenvironment; TIM-3, T-cell membrane protein 3; LAG-3, lymphocyte activation gene 3; CDI37, cluster of differentiation 137; PT stage, pathologic $\mathrm{T}$ stage; t-SNE, t-distributed stochastic neighbor embedding; TCGA,

The Cancer Genome Atlas; HR, hazard ratio; Cls, confidence intervals; GEPIA, Gene Expression Profiling Interactive Analysis.

(Figure 5C), and tumor histology (Figure 5E). We found that the patients with advanced tumor grade were significantly associated with a higher percentage of $\mathrm{CD} 4+\mathrm{T}$ cells
$(P=0.005)$ and lower percentage of CD8+ T cells $(P=$ 0.025 , Figure $5 \mathrm{~A})$. We further explored the relationship between the expression of these ICs in $\mathrm{CD} 4+/ \mathrm{CD} 8+$ $\mathrm{T}$ cells and pathological characteristics to better understand the basis for this heterogeneity (Figure 5B, D and F). Interestingly, the advanced tumor pathologic $\mathrm{T}$ stage and the non-papillary tumor were statistically correlated with a lower percentage of CD4+/CD8+ CD39+ T cells $(P=$ 0.041 , Figure 5D; $P=0.038$, Figure 5F). Normally, the advanced tumor pathologic $\mathrm{T}$ stage and non-papillary tumor indicated worse prognosis, and the percentage of CD4+/CD8+ CD39+ T cells in advanced tumor pathologic $\mathrm{T}$ stage and non-papillary tumor was significantly decreased at present study. These results indicated that $\mathrm{CD} 4+/ \mathrm{CD} 8+$ CD39+ T cells may play a vital role in tumor development of BLCA. Therefore, we further explore the possible function of CD39 in CD4+/CD8+ T cells.

\section{CD8+CD39+ T Cells Mediate Anti-Tumor Cytotoxicity}

To investigate the potential function of these $\mathrm{T}$ cells, we sorted the mouse $\mathrm{CD} 4+\mathrm{CD} 39+\mathrm{T}$ cells,
A $\mathrm{CD} 4+\mathrm{CD} 39+$

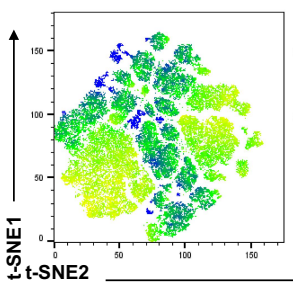

B CD4+PD -1+

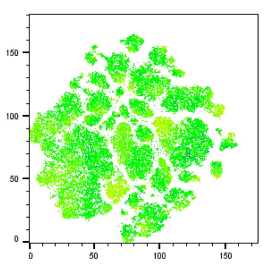

C ${ }_{\text {CD4+TIM-3+ }}$

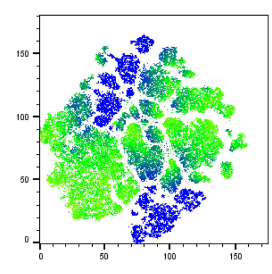

D CD4+LAG-3+

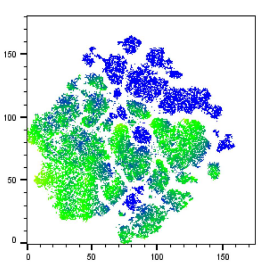

E CD4+OX40+

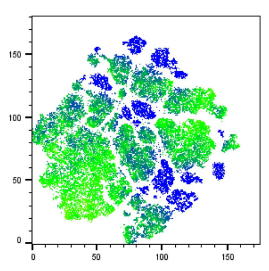

F ${ }_{\mathrm{CD} 4+4-1 \mathrm{BB}+}$

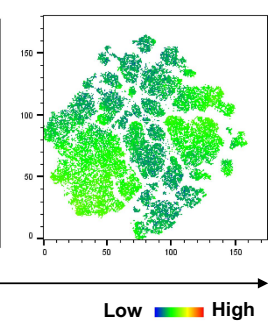

L CD8+4-1BB+
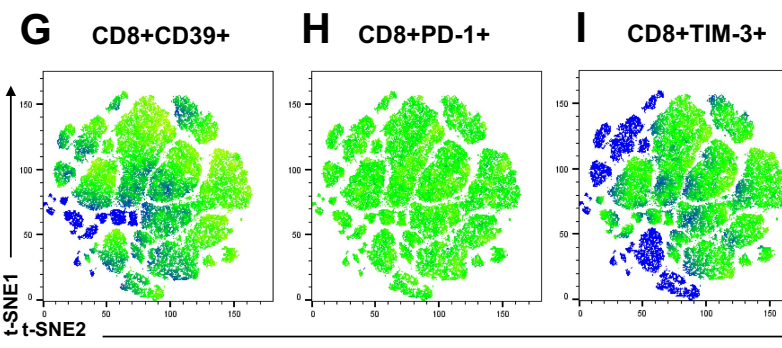

J CD8+LAG3+
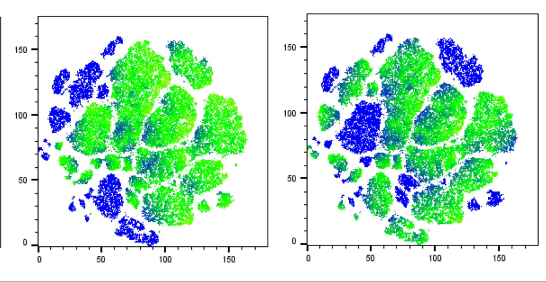

K $\mathrm{CD} 8+0 \times 40+$
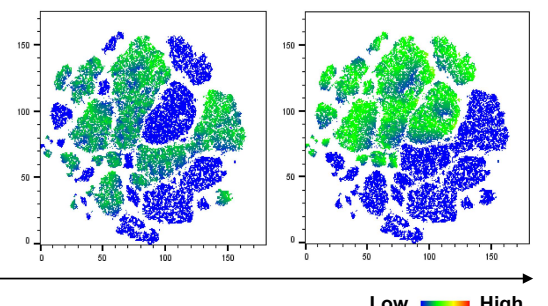

M
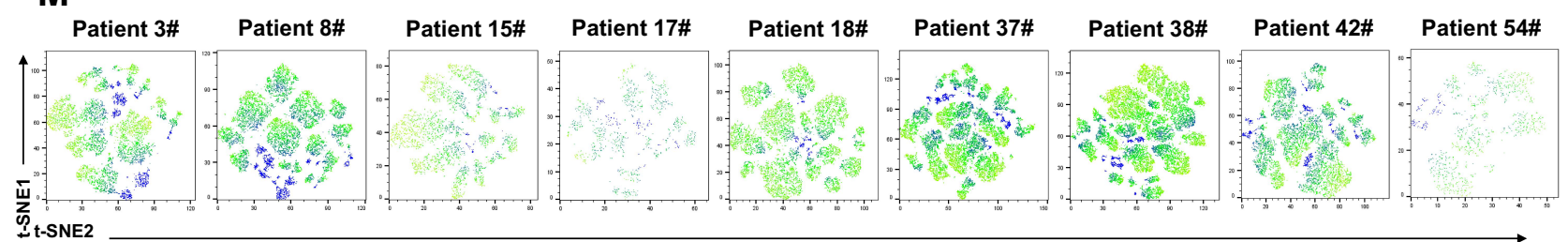

Figure 4 The distribution of immune checkpoints expression in CD4+/CD8+ T cells with different tumor grade, tumor stage, and tumor histology of BLCA patients ( $\mathrm{n}=9$, the clinicopathological characters of 9 patients is showed in Supplement Table I). (A-F) The t-distributed stochastic neighbor embedding (t-SNE) map of CD4+ T cells; (GL) The t-SNE map of CD8+ T cells; (M) The t-SNE map of CD8+CD39+ T cells. 

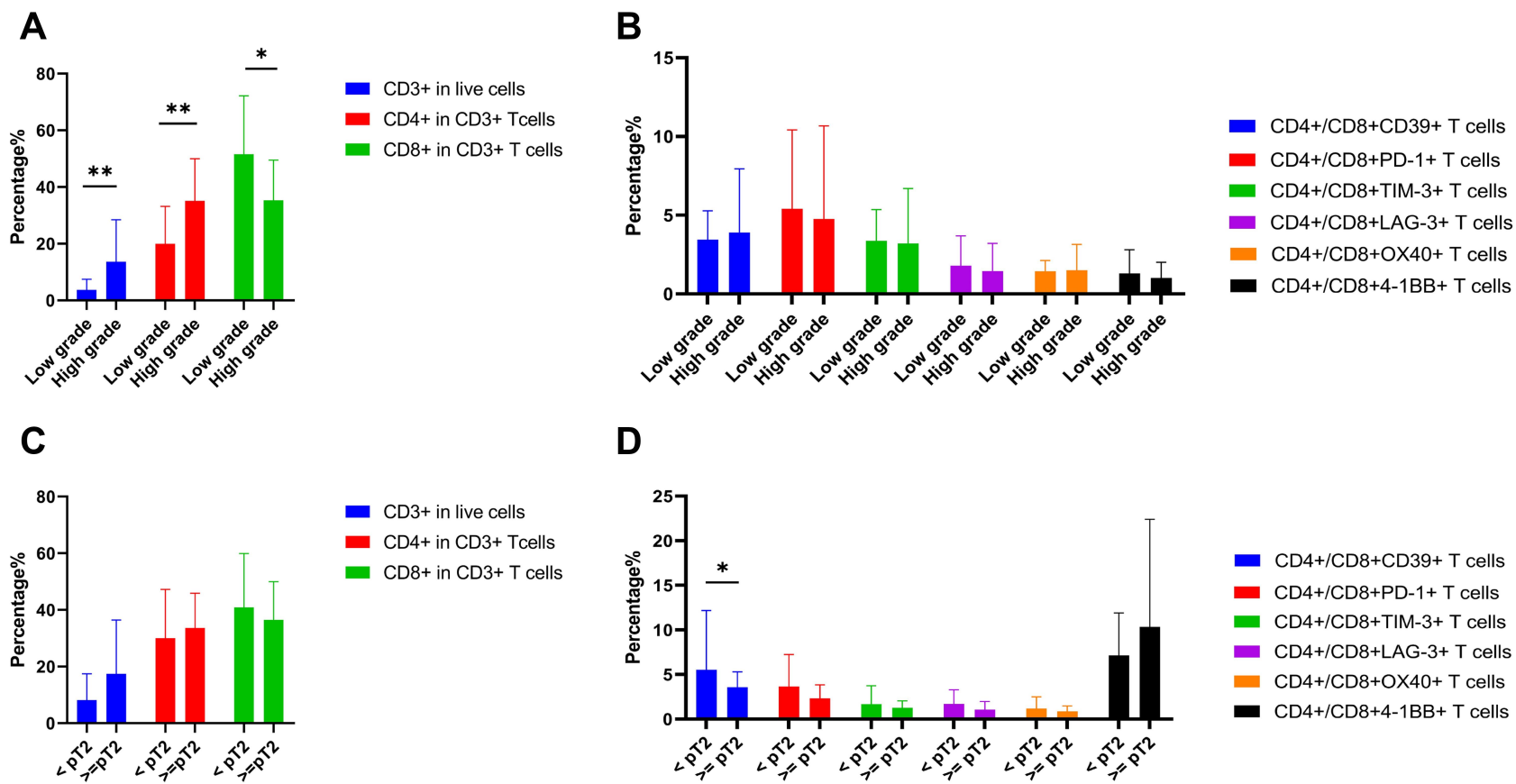

D
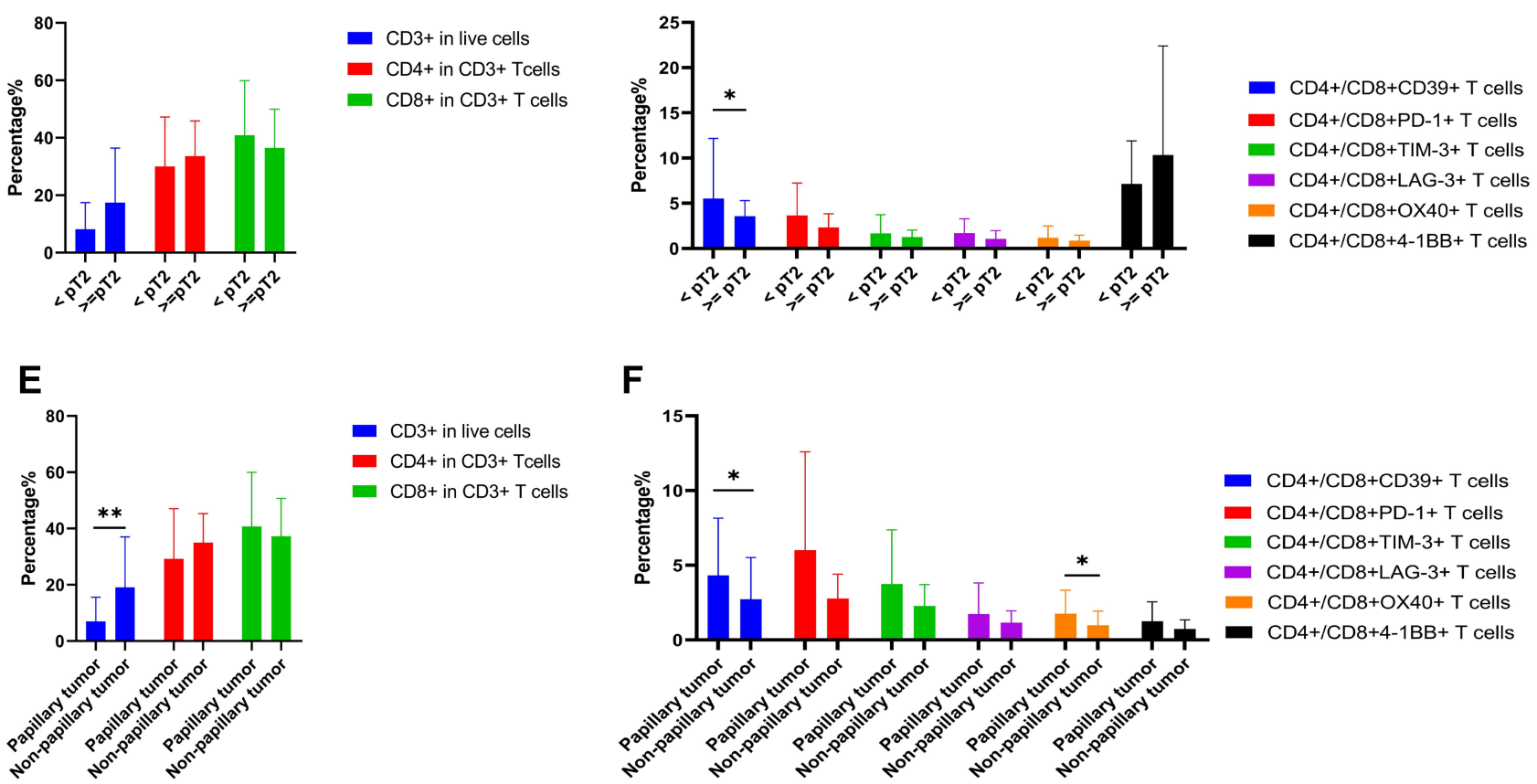

Figure 5 The relationship between the distribution of different immune checkpoints in T cells and pathological characteristics of BLCA patients. (A, B) Tumor grade; (C, D) Tumor pathologic T stage; (E, F) Tumor histology. $* P<0.05 ; * * P<0.01$.

CD4+CD39- $\mathrm{T}$ cells, CD8+CD39+ $\mathrm{T}$ cells, and CD8 + CD39- $\mathrm{T}$ cells by flow cytometry and co-cultured them with MB49 bladder cancer cell lines in vitro, respectively. Significantly, the $\mathrm{CD} 8+\mathrm{CD} 39+\mathrm{T}$ cells group showed a stronger tumor-killing effect. In contrast, little to no tumor cell killing was observed in other $\mathrm{T}$ cell populations. Besides, the IFN- $\gamma$ secretion levels of different co-culture groups showed that the CD8+CD39 $+\mathrm{T}$ cells co-cultured with autologous tumor cells produced a higher level of IFN- $\gamma$. Taken together, our results suggested that $\mathrm{CD} 8+\mathrm{CD} 39+\mathrm{T}$ cells could mediate anti-tumor cytotoxicity in BLCA (Figure 6).

\section{The Relationship Between CD39}

\section{Expression and Other Immune} Checkpoints Expression of CD8+ T Cells in BLCA Patients

We next investigated the relationship between CD39 expression and PD-1, TIM-3, LAG-3, OX40, 4-1BB expression of $\mathrm{CD} 8+\mathrm{T}$ Cells in BLCA patients (Figure 7). The expression of CD39 in CD8+ T cells was significantly associated with TIM-3 ( $\mathrm{r}=0.6247, P<0.0001)$, LAG-3 ( $\mathrm{r}=0.3699, P=0.0159)$, OX40 ( $\mathrm{r}=0.4296, P=$ $0.0045)$, and $4-1 \mathrm{BB}(\mathrm{r}=0.3633, P=0.0180)$. According 


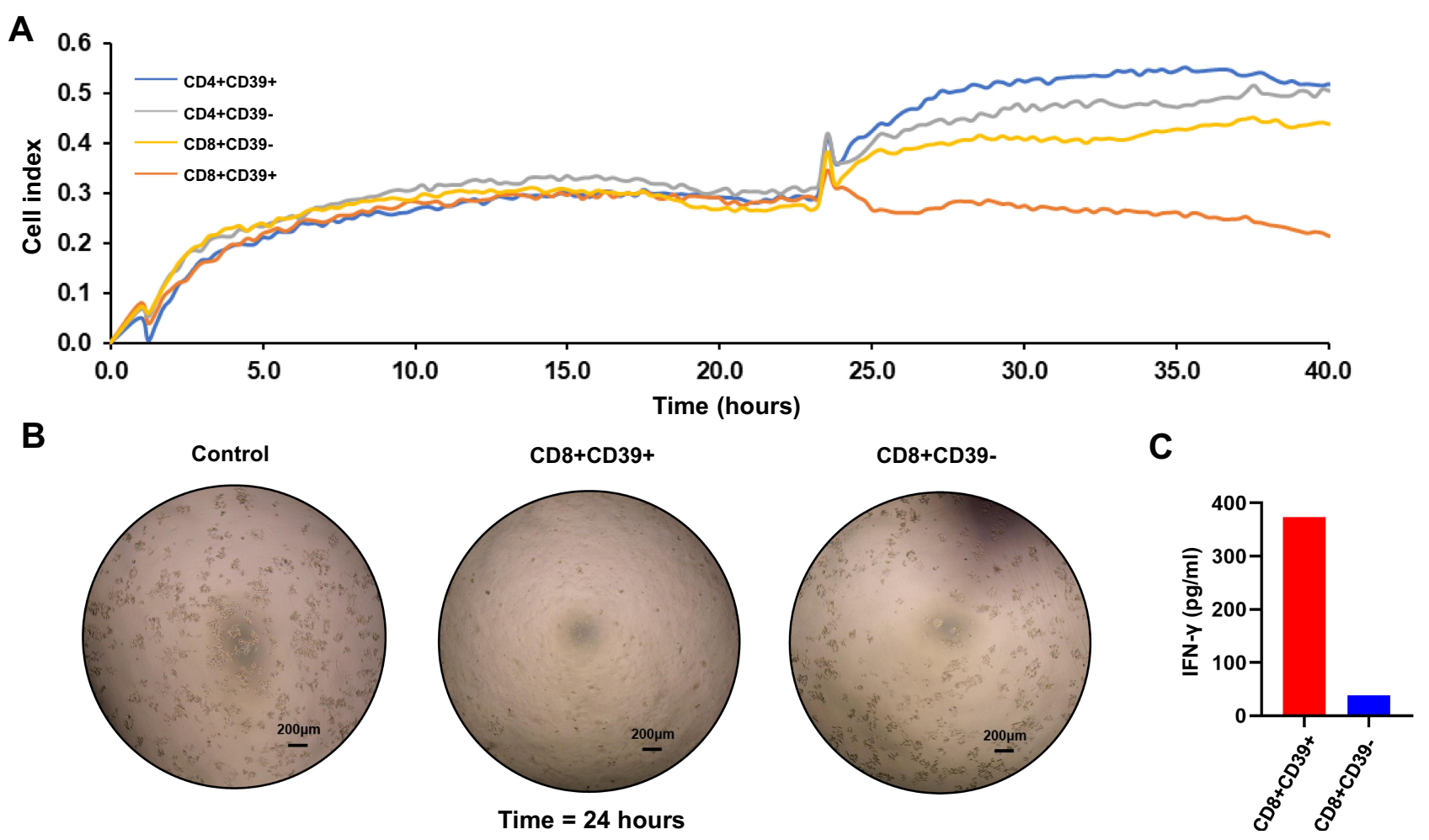

Figure 6 The anti-tumor cytotoxicity assay of sorted T cells. (A) The tumor cells survival curve for sorted T cells co-cultured with MB49 bladder cancer cell lines in vitro; (B) The images for co-culture sorted T cells and MB49 tumor cells (24 hours).; (C) The IFN- $\gamma$ secretion levels of different co-culture groups.

to the median (\%) of $\mathrm{CD} 8+\mathrm{CD} 39+\mathrm{T}$ cells, all patients were divided into two groups. The significantly different expression of these immune checkpoints between the low expression group and the high expression group is shown in Figure 8. Except for PD-1, other ICs have significant differences in the different expression CD39 groups. Besides, we also described the frequency of $\mathrm{CD} 3+$ $\mathrm{T}$ cells, CD4 $+\mathrm{T}$ cells, CD8 $+\mathrm{T}$ cells, CD8+CD39+ T cells, CD8+PD-1+ T cells, CD8+TIM-3+ T cells, CD8 +LAG-3+ T cells, CD8+OX40+ T cells, and CD8+4-1BB+ $\mathrm{T}$ cells in BLCA patients (Figure 9) to provide a rough evaluation about the number of TILs that can be directly extracted from tumor samples that are routinely resected.

\section{Discussion}

Bladder cancer is one of the most common malignant tumors and correlates with high morbidity, mortality and medical cost. Although a variety of treatment options for this kind of cancer have been developed, the treatment of BLCA remains a serious problem now. In recent years, the most popular therapeutic method in tumors is immunotherapy that modifies the immune status of patients. However, due to the huge heterogeneity of BLCA, the anti-PD-1/PD-
L1 immune checkpoint therapy benefits only about $30 \%$ of patients. ${ }^{5}$ Another tumor immunotherapy method, namely ACT using tumor-infiltrating lymphocytes (TILs), has demonstrated very high objective response rates $(50 \%$ $72 \%$ ), and long-lasting complete tumor regression in up to $20-25 \%$ of treated patients in clinical trials of melanoma. ${ }^{19,20}$ However, the TILs therapy in BLCA has not been further studied. Thus, new immune checkpoints or TILs therapy are still awaiting to be discovered to improve the BLCA patient's prognosis.

In the present study, we first explored the expression of 5 potential ICs targets (TIM-3, LAG-3, OX40, 4-1BB and CD39) in bladder cancer and their impacts on prognosis through public databases, because all of them have corresponding drugs in clinical trials in other tumors. We found that the transcriptional expression of CD39 in BLCA was significantly lower than CD39 in normal tissue, and the elevated mRNA expression of CD39 was related to the advanced tumor stage, which indicated that the CD39 expression may be associated with the prognosis of BLCA patients. We further used the Kaplan-Meier curve analysis to assess the relationship between the expression of the 5 ICs expression and the overall survival of patients. 
A CD39 and PD-1

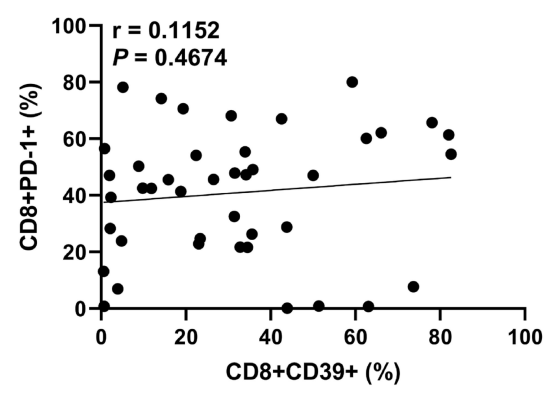

B CD39 and TIM-3

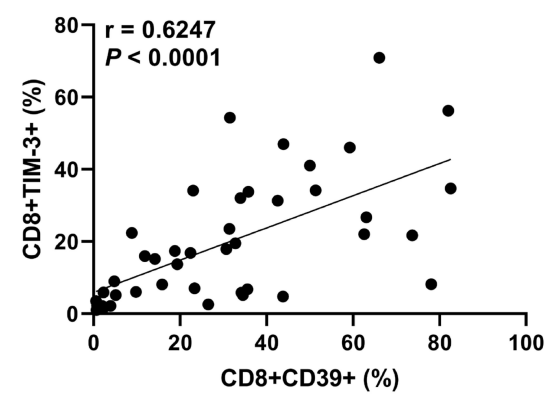

C CD39 and LAG-3

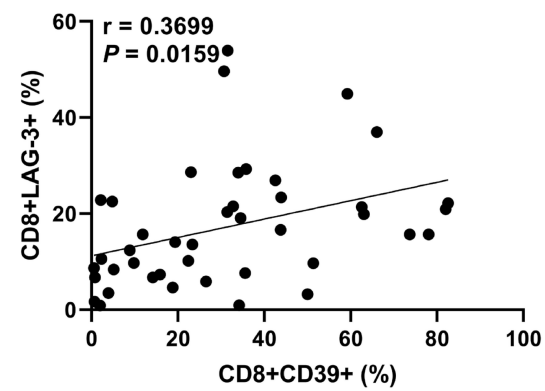

D CD39 and OX40

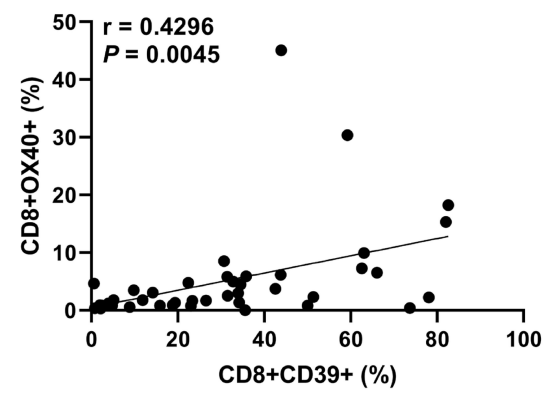

E CD39 and 4-1BB

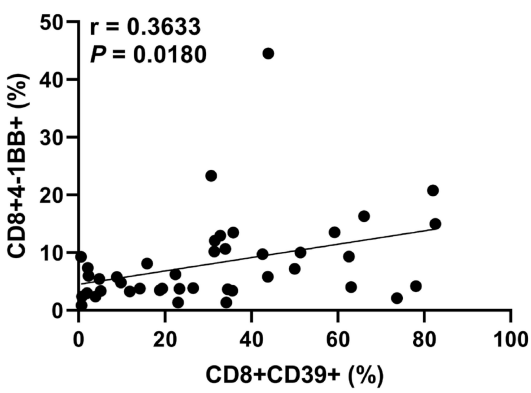

Figure 7 The relationship between CD39 expression and other immune checkpoints expression of CD8+ T Cells in BLCA patients. (A) PD-I, (B) TIM-3, (C) LAG-3, (D) OX40, (E) 4-IBB.
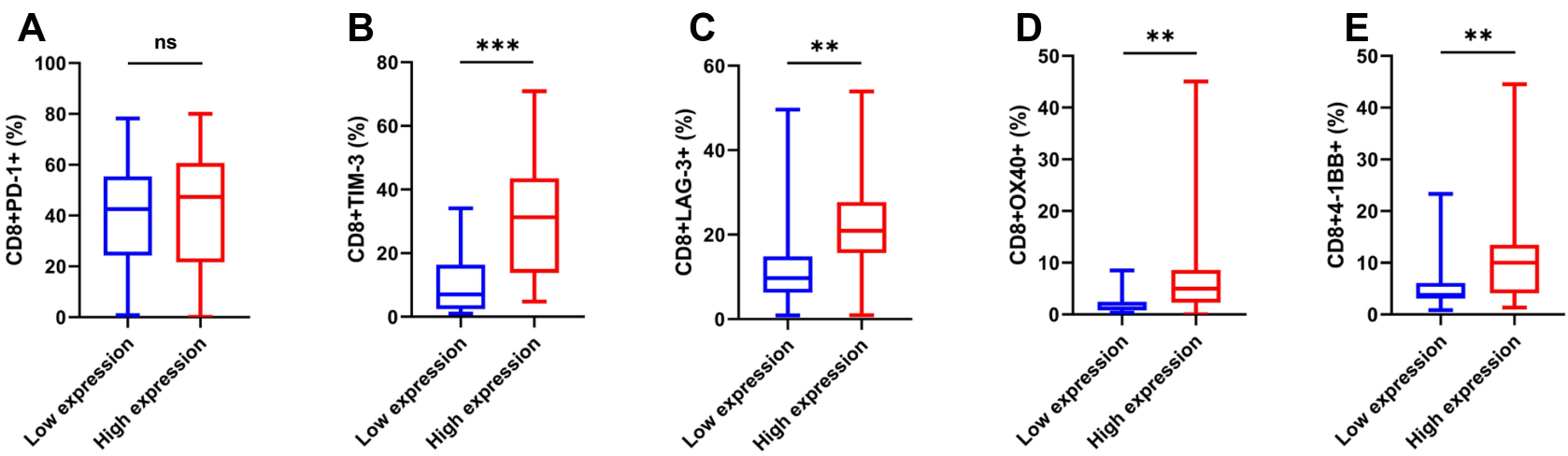

Figure 8 The expression of immune checkpoints analysis of CD8+ T cells stratified by CD39 expression. (A) PD-I, (B) TIM-3, (C) LAG-3, (D) OX40, (E) 4-IBB. $* * P<0.01$; *** $P<0.001$; ns, $P>0.05$.

Intriguingly, the result revealed that BLCA patients with higher mRNA expression of CD39 may gain shorter survival time, which was different from other ICs in BLCA and the conclusion of previous studies. ${ }^{15,16}$

CD39, the rate-limiting enzyme in the hydrolysis of extracellular ATP/ADP, participates in the generation of adenosine, potentially playing a vital role in TME. ${ }^{21,22}$ During the past decade, the role of CD39 in tumorigenesis has been investigated in various cancers, ${ }^{23-25}$ normally suggesting that increased CD39 expression may be an independent poor prognostic parameter. However, with the in-depth study of various cells in TME, more and more evidence shows that $\mathrm{CD} 39$ plays multiple biological functions on the surface of different cells. ${ }^{9}$ The expression of CD39 was also detected on T cells, especially on CD8 $+T$ cells with hallmarks of chronic antigenic stimulation at the tumor site and was associated with clinical beneficial factors in multiple cancers. ${ }^{15,26}$ An earlier study reported that $\mathrm{CD} 39$ is a marker for $\mathrm{CD} 8+\mathrm{T}$ cells to mediate specific killer function. ${ }^{27}$ Recent research showed that the lack of 
A

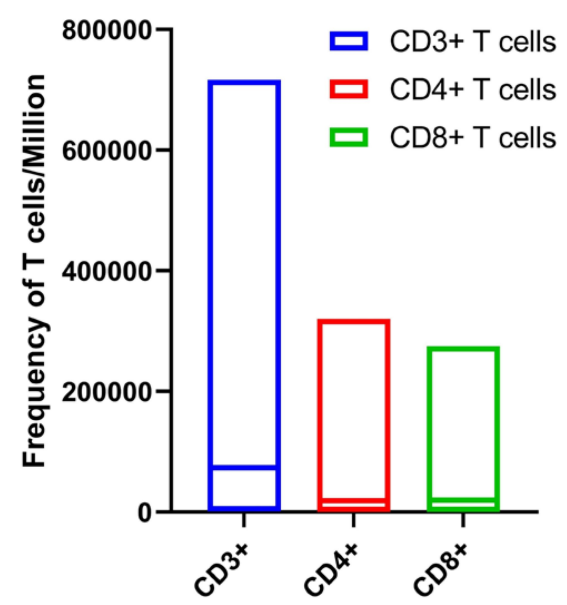

B

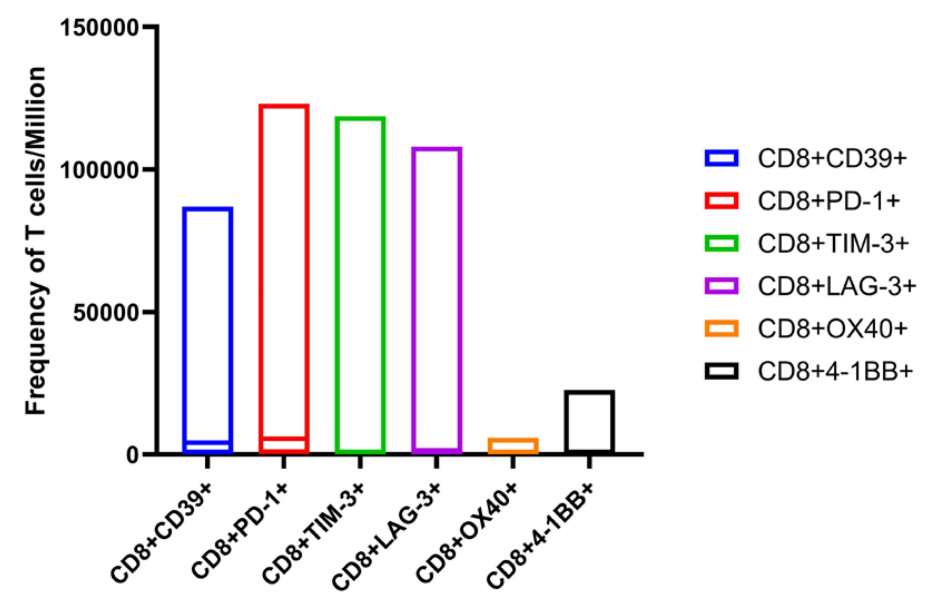

Figure 9 The frequency of different $T$ cells populations. (A) The frequency of CD3+ T cells, CD4+ $T$ cells, and CD8+ $T$ cells in $T$ cells/I0 $0^{6}$ of BLCA patients; $(B)$ The frequency of CD8+CD39+ T cells, CD8+PD-I+T cells, CD8+TIM-3+ T cells, CD8+LAG-3+ T cells, CD8+OX40+ T cells, and CD8+4-IBB+ T cells in T cells/I0 ${ }^{6}$ of BLCA patients.

CD39 in CD8+TILs defines a subset of cells that lack chronic antigen-stimulating characteristics at the tumor site, and measuring the expression of CD39 may be a convenient method to quantify or isolate bystander $\mathrm{T}$ lymphocytes in colorectal and lung tumors. ${ }^{26}$ Studies have also shown that if patients with head and neck cancer have higher frequencies of CD103+CD39+CD8 TILs in their tumor tissue, they will obtain better overall survival. ${ }^{15}$ Obviously, these conclusions are contrary to the conclusions obtained by our analysis of public databases. However, the expression of CD39 in BLCA has not been clarified, especially the CD39 expression in T cells.

As we realized that these conclusions are based on discussing the expression of CD39 on T cells, the limitation of the public database is that it contains the expression of CD39 of all cells in whole tumor tissues. As we all know, CD39 can be expressed not only on T cells, but also on tumor cells and other cells. Therefore, we next mainly explored the PD-1, TIM-3, LAG-3, OX40, 4-1BB, and CD39 expressions in $\mathrm{T}$ cells, especially in $\mathrm{CD} 4+/ \mathrm{CD} 8+$ $\mathrm{T}$ cells by flow cytometry. We found that the CD39 expression of $\mathrm{CD} 4+/ \mathrm{CD} 8+\mathrm{T}$ cells was significantly associated with the tumor pathological T stage and tumor histology of BLCA patients. As expected, the non-muscular invasion bladder tumor tended to express the higher CD39 and the papillary tumor also had higher expression of CD39, which was different from the status of the CD39 expression in whole bladder tumor. Moreover, the expression of CD39 in CD8+ T cells was notably correlated with TIM-3. TIM-3 is a type I transmembrane protein that was discovered in a study to identify novel cell surface molecules that would mark IFN- $\gamma$-producing Th1 and Tc1 cells. ${ }^{28}$ It has been well-documented found in tumors, including multiple cancers, ${ }^{29-31}$ and obtained attention as a potential biomarker for tumor immunotherapy in recent years. The co-expression of CD39 and TIM-3 may provide a novel ICIs treatment strategy to achieve better effects on the immune response. In addition, the expression of CD39 and PD-1 on CD8 T cells was not significantly related, suggesting that immunotherapy for CD39 can be used as a supplementary method for patients who do not respond to anti-PD-1 treatment.

In recent years, TILs therapy that enhances the immune function of T cells in TME plays an increasingly important role in immunotherapy, especially for patients who do not respond to PD-1 ICIs. ${ }^{32}$ Studies have shown that the existence of TILs was significantly correlated with improved survival outcome in various tumors, including esophageal, breast, renal, and colon carcinoma. ${ }^{33-36}$ However, only a part of T cells in TILs extracted from tumor tissue can recognize tumor cells, which may be due to the existence of a large number of bystander $T$ cells in TILs. At present, PD-1 and 4-1BB have been proposed as markers for the tumor-reactive biomarker in the tumor. ${ }^{13,14}$ Nevertheless, considering the huge heterogeneity of patients and tumors, only PD-1 and $4-1 \mathrm{BB}$ as biomarkers of tumor-reactive TILs are not enough. To investigate the potential biomarker of tumor-reactive TILs, we sorted the CD4+CD39+ T cells, CD4+CD39- T cells, CD8+CD39+ $T$ cells, and CD8+CD39- $T$ cells and co-cultured with 
MB49 bladder cancer cell lines in vitro. Our results showed that $\mathrm{CD} 8+\mathrm{CD} 39+\mathrm{T}$ cells could recognize and kill bladder cancer cells. In former literature, CD39 has been proposed as a biomarker to identify tumor-reactive $\mathrm{CD} 8+\mathrm{T}$ cells in lung cancer, colorectal cancer, and head and neck cancer. ${ }^{4,26,37}$ Although CD39 was also expressed on the CD4+ $\mathrm{T}$ cells, CD4+ $\mathrm{T}$ cells mainly play a role in instigating and shaping adaptive immune responses. A previous study also showed that $\mathrm{CD} 4+$ regulatory $\mathrm{T}$ cells (Tregs) express CD39, which may provide a possible explanation for $\mathrm{CD} 4+\mathrm{CD} 39+\mathrm{T}$ cells could not kill tumor cells. ${ }^{22}$ While CD8+ T cells are the better population to target tumor cells, as they could detect intracellular antigens that are presented by MHC class I molecules expressed by all tumor cell types. ${ }^{38}$ However, not all CD8+ $\mathrm{T}$ cells could recognize and kill tumor cells, the identification of functional CD8 $+\mathrm{T}$ cells population is crucial in tumor immunotherapy. In the present study, we suggested that CD39 could serve as a marker for the identification and isolation of tumorspecific CD8+ T cells in BLCA.

\section{Conclusion}

In summary, we proposed that the elevated CD39 expression of CD4+/CD8 $+\mathrm{T}$ cells was significantly associated with superficial bladder tumors $(\mathrm{pT}<2)$ and papillary tumors in BLCA. Moreover, the CD8+CD39+ $\mathrm{T}$ cells mediate anti-tumor cytotoxicity in BLCA, which will contribute to isolating specific cytotoxic $\mathrm{T}$ cell population and improving their activity, and may aid in the development of effective CD8+ T-cell-based immunotherapies. The identification of CD39 as a biomarker for tumor-reactive CD8 $+\mathrm{T}$ cells will also be highly useful for research on the effectiveness of several therapeutic methods for BLCA patients, including ICIs, monoclonal antibodies, and vaccines. To our knowledge, this is the first study proposing the potential therapeutic value of $\mathrm{CD} 8+\mathrm{CD} 39+\mathrm{T}$ cells in patients with BLCA, and our findings warrant further research and external validation.

\section{Data Sharing Statement}

The datasets analyzed during the current study are not publicly available as the Ethics Committee of Nanjing Drum Tower Hospital does not have permission to provide the data of individual participants, but they are available from the corresponding author (Rong Yang) on reasonable request.

\section{Ethics Approval and Consent to Participate}

The present study was designed and performed in accordance with the Declaration of Helsinki and was approved by the Ethics Committee of Nanjing Drum Tower Hospital (No. 2019-0127), and written informed consent was obtained from each patient.

\section{Acknowledgments}

This study was supported by the National Natural Science Foundation of China (81772727 and 81772710), the General Financial Grant from the China Postdoctoral Foundation (2016M591831) and the Nanjing Science and Technology Development Project (YKK16073).

\section{Author Contributions}

All authors made substantial contributions to conception and design, acquisition of data, or analysis and interpretation of data; took part in drafting the article or revising it critically for important intellectual content; agreed on the journal to which the article will be submitted; gave final approval of the version to be published; and agree to be accountable for all aspects of the work.

\section{Disclosure}

The authors report no conflicts of interest in this work.

\section{References}

1. Chen W, Zheng R, Baade PD, et al. Cancer statistics in China, 2015. CA Cancer J Clin. 2016;66(2):115-132. doi:10.3322/caac.21338

2. Bray F, Ferlay J, Soerjomataram I, Siegel RL, Torre LA, Jemal A. Global cancer statistics 2018: GLOBOCAN estimates of incidence and mortality worldwide for 36 cancers in 185 countries. CA Cancer J Clin. 2018;68(6):394-424. doi:10.3322/caac.21492

3. Berdik C. Unlocking bladder cancer. Nature. 2017;551(7679):S34S35. doi:10.1038/551S34a

4. Thommen DS, Koelzer VH, Herzig P, et al. A transcriptionally and functionally distinct PD-1(+) CD8(+) T cell pool with predictive potential in non-small-cell lung cancer treated with PD-1 blockade. Nat Med. 2018;24(7):994-1004. doi:10.1038/s41591-018-0057-z

5. Sharma P, Callahan MK, Bono P, et al. Nivolumab monotherapy in recurrent metastatic urothelial carcinoma (CheckMate 032): a multicentre, open-label, two-stage, multi-arm, Phase 1/2 trial. Lancet Oncol. 2016;17(11):1590-1598. doi:10.1016/S1470-2045(16) 30496-X

6. Anderson AC, Joller N, Kuchroo VK. Lag-3, Tim-3, and TIGIT: co-inhibitory Receptors with Specialized Functions in Immune Regulation. Immunity. 2016;44(5):989-1004. doi:10.1016/j.immuni.20 16.05.001

7. Jensen SM, Maston LD, Gough MJ, et al. Signaling through OX40 enhances antitumor immunity. Semin Oncol. 2010;37(5):524-532. doi:10.1053/j.seminoncol.2010.09.013 
8. Chester C, Sanmamed MF, Wang J, Melero I. Immunotherapy targeting 4-1BB: mechanistic rationale, clinical results, and future strategies. Blood. 2018;131(1):49-57. doi:10.1182/blood-2017-06-741041

9. Moesta AK, Li X-Y, Smyth MJ. Targeting CD39 in cancer. Nat Rev Immunol. 2020;20(12):739-755. doi:10.1038/s41577-020-0376-4

10. June CH, Sadelain M. Chimeric Antigen Receptor Therapy. $N$ Engl J Med. 2018;379(1):64-73. doi:10.1056/NEJMra1706169

11. Rosenberg SA, Yang JC, Sherry RM, et al. Durable complete responses in heavily pretreated patients with metastatic melanoma using T-cell transfer immunotherapy. Clin Cancer Res. 2011;17 (13):4550-4557. doi:10.1158/1078-0432.CCR-11-0116

12. Rapoport AP, Stadtmauer EA, Binder-Scholl GK, et al. NY-ESO-1-specific TCR-engineered T cells mediate sustained antigen-specific antitumor effects in myeloma. Nat Med. 2015;21(8):914-921. doi:10.1038/ nm. 3910

13. Gros A, Robbins PF, Yao X, et al. PD-1 identifies the patient-specific CD8+ tumor-reactive repertoire infiltrating human tumors. J Clin Invest. 2014;124(5):2246-2259. doi:10.1172/JCI73639

14. Ye Q, Song DG, Poussin M, et al. CD137 accurately identifies and enriches for naturally occurring tumor-reactive T cells in tumor. Clin Cancer Res. 2014;20(1):44-55. doi:10.1158/1078-0432.CCR-13-0945

15. Duhen T, Duhen R, Montler R, et al. Co-expression of CD39 and CD103 identifies tumor-reactive CD8 T cells in human solid tumors. Nat Commun. 2018;9(1):2724. doi:10.1038/s41467-018-05072-0

16. Workel H, van Rooij N, Plat A, et al. Transcriptional Activity and Stability of CD39+CD103+CD8+ T Cells in Human High-Grade Endometrial Cancer. Int J Mol Sci. 2020;21(11):3770. doi:10.3390/ ijms21113770

17. Svane IM, Verdegaal EM. Achievements and challenges of adoptive $\mathrm{T}$ cell therapy with tumor-infiltrating or blood-derived lymphocytes for metastatic melanoma: what is needed to achieve standard of care? Cancer Immunol Immunother. 2014;63(10):1081-1091. doi:10.1007/ s00262-014-1580-5

18. Vijayan D, Young A, Teng MWL, Smyth MJ. Targeting immunosuppressive adenosine in cancer. Nat Rev Cancer. 2017;17(12):765. doi:10.1038/nrc.2017.110

19. Allard B, Longhi MS, Robson SC, Stagg J. The ectonucleotidases CD39 and CD73: novel checkpoint inhibitor targets. Immunol Rev. 2017;276(1):121-144.

20. Cai XY, Ni XC, Yi Y, et al. Overexpression of CD39 in hepatocellular carcinoma is an independent indicator of poor outcome after radical resection. Medicine. 2016;95(40):e4989. doi:10.1097/MD.000 0000000004989

21. Künzli BM, Berberat PO, Giese T, et al. Upregulation of CD39/ NTPDases and P2 receptors in human pancreatic disease. Am J Physiol Gastrointest Liver Physiol. 2007;292(1):G223-G230. doi:10.1152/ajpgi.00259.2006

22. Wu J, Wang Y-C, $\mathrm{Xu} \mathrm{W-H,} \mathrm{et} \mathrm{al.} \mathrm{High} \mathrm{Expression} \mathrm{of} \mathrm{CD39} \mathrm{is}$ Associated with Poor Prognosis and Immune Infiltrates in Clear Cell Renal Cell Carcinoma. Onco Targets Ther. 2020;13:10 453-10464. doi:10.2147/OTT.S272553

23. Simoni Y, Becht E, Fehlings M, et al. Bystander CD8(+) T cells are abundant and phenotypically distinct in human tumour infiltrates. Nature. 2018;557(7706):575-579. doi:10.1038/s41586-018-0130-2

24. Gouttefangeas C, Mansur I, Schmid M, et al. The CD39 molecule defines distinct cytotoxic subsets within alloactivated human CD8-positive cells. Eur J Immunol. 1992;22(10):2681-2685. doi:10. 1002/eji.1830221031
25. Monney L, Sabatos CA, Gaglia JL, et al. Th1-specific cell surface protein Tim-3 regulates macrophage activation and severity of an autoimmune disease. Nature. 2002;415(6871):536-541. doi:10.103 8/415536a

26. Piao YR, Piao LZ, Zhu LH, Jin ZH, Dong XZ. Prognostic value of T cell immunoglobulin mucin-3 in prostate cancer. Asian Pacific j Cancer Prevent. 2013;14(6):3897-3901. doi:10.7314/APJCP.2013. 14.6.3897

27. Yuan J, Jiang B, Zhao H, Huang Q. Prognostic implication of TIM-3 in clear cell renal cell carcinoma. Neoplasma. 2014;61(1):35-40. doi:10.4149/neo_2014_006

28. Yang M, Yu Q, Liu J, et al. T-cell immunoglobulin mucin-3 expression in bladder urothelial carcinoma: clinicopathologic correlations and association with survival. J Surg Oncol. 2015;112(4):430-435. doi:10.1002/jso. 24012

29. Sarnaik A, Khushalani NI, Chesney JA, et al. Safety and efficacy of cryopreserved autologous tumor infiltrating lymphocyte therapy (LN-144, lifileucel) in advanced metastatic melanoma patients who progressed on multiple prior therapies including anti-PD-1. J Clin Oncol. 2019;37(15_suppl):2518. doi:10.1200/JCO.2019.37.15_suppl. 2518

30. Sato E, Olson SH, Ahn J, et al. Intraepithelial CD8+ tumor-infiltrating lymphocytes and a high $\mathrm{CD} 8+$ /regulatory $\mathrm{T}$ cell ratio are associated with favorable prognosis in ovarian cancer. Proc Natl Acad Sci U S A. 2005;102(51):18538-18543. doi:10.10 73/pnas.0509182102

31. Schumacher K, Haensch W, Röefzaad C, Schlag PM. Prognostic significance of activated CD8(+) T cell infiltrations within esophageal carcinomas. Cancer Res. 2001;61(10):3932-3936.

32. Naito Y, Saito K, Shiiba K, et al. CD8+ T cells infiltrated within cancer cell nests as a prognostic factor in human colorectal cancer. Cancer Res. 1998;58(16):3491-3494.

33. Nakano O, Sato M, Naito Y, et al. Proliferative activity of intratumoral CD8(+) T-lymphocytes as a prognostic factor in human renal cell carcinoma: clinicopathologic demonstration of antitumor immunity. Cancer Res. 2001;61(13):5132-5136.

34. van den Bulk J, Verdegaal EME, Ruano D, et al. Neoantigen-specific immunity in low mutation burden colorectal cancers of the consensus molecular subtype 4. Genome Med. 2019;11(1):87. doi:10.1186/ s13073-019-0697-8

35. Borst J, Ahrends T, Bąbała N, Melief CJM, Kastenmüller W. CD4+ $\mathrm{T}$ cell help in cancer immunology and immunotherapy. Nat Rev Immunol. 2018;18(10):635-647. doi:10.1038/s41577-018-0044-0

36. Chandrashekar DS, Bashel B, Balasubramanya SAH, et al. UALCAN: a Portal for Facilitating Tumor Subgroup Gene Expression and Survival Analyses. Neoplasia. 2017;19(8):649-658. doi:10.1016/j.neo.2017.05.002

37. Nagy A, Lanczky A, Menyhárt O, Győrffy B. Validation of miRNA prognostic power in hepatocellular carcinoma using expression data of independent datasets. Sci Rep. 2018;8(1):9227. doi:10.1038/ s41598-018-27521-y

38. Tang Z, Li C, Kang B, Gao G, Li C, Zhang Z. GEPIA: a web server for cancer and normal gene expression profiling and interactive analyses. Nucleic Acids Res. 2017;45(W1):W98-W102. doi:10.10 93/nar/gkx247 


\section{Publish your work in this journal}

OncoTargets and Therapy is an international, peer-reviewed, open access journal focusing on the pathological basis of all cancers, potential targets for therapy and treatment protocols employed to improve the management of cancer patients. The journal also focuses on the impact of management programs and new therapeutic

Submit your manuscript here: https://www.dovepress.com/oncotargets-and-therapy-journal agents and protocols on patient perspectives such as quality of life, adherence and satisfaction. The manuscript management system is completely online and includes a very quick and fair peer-review system, which is all easy to use. Visit http://www.dovepress.com/ testimonials.php to read real quotes from published authors. 